\title{
Smart experiential paths and Historical Urban Landscape: a case of sustainable enhancement
}

\author{
M. Sepe \\ IRAT C.N.R., DiARC University of Naples Federico II, Italy
}

\begin{abstract}
One of the most recent modalities used for the local development of a territory consists in the construction of integrated systems for the management of cultural resources to be benefited through experiential paths. These paths are designed in order to identify existing heritage and, at the same time to support and/or stimulate the development of creative industries.

The experiential knowledge of a place can be further improved and virtualized using smart technologies to be applied by the territorial system in all its complexity. In order to frame the issue of territorial experiential paths, the proposed study, carried out in the framework of the research "The historic urban landscape as a resource for local development: an innovative approach for smart strategies to value creation" - within the PRIN - Project of Relevant Italian National Interest, specifically related to the Unesco Recommendation (2011) on the Historical Urban Landscape, aims to illustrate their definitional aspects and its evolution, and how to sustainably organize the territory in order to accommodate those paths. The synthesis of the case study of Pompeii, in the course of development, devoted to identify the cultural and identity resources in order to both widen and differentiate those archaeological ones and create a smart sustainable experiential knowledge of the territory, concludes the contribution.

Keywords: experiential paths, place identity, smart innovation, sustainable development, creativity.
\end{abstract}

\section{Introduction}

The introduction to the UNESCO Recommendation [1] on the Historical Urban Landscape, article 3, assumes: "Urban heritage, including its tangible and intangible components, constitutes a key resource in enhancing the liveability of 
urban areas, and fosters economic development and social cohesion in a changing global environment. As the future of humanity hinges on the effective planning and management of resources, conservation has become a strategy to achieve a balance between urban growth and quality of life on a sustainable basis".

From this statement the need for the identification of both tangible and intangible resources both for the development and liveability of an area and its socio-economic development is declared. One of the most recent modality used for local development of a territory consists in the construction of integrated systems for the management of cultural resources to be benefited through experiential paths. These paths are designed in order to identify existing heritage and, at the same time to support and/or stimulate the development of creative industries [2]. The experiential knowledge of a place can be further improved and virtualized using smart technologies to be applied by the territorial system in all its complexity. The strategic dimensions upon which the vision of the smart cities is based concern mobility, environment, tourism, culture, knowledge economy and quality of life. Faster movements, supported by sustainable transport and solutions on mobility, tourism and culture - based on an enhancement able to connect green networks and systems of cultural values also through the construction of thematic routes, and the construction of a virtual image that can improve competitiveness are all elements which contribute to the transformation and promotion of the territory in smart key [3]. In order to frame the issue of territorial experiential paths, the proposed study, carried out in the framework of the research "The historic urban landscape as a resource for local development: an innovative approach for smart strategies to value creation" - within the PRIN - Project of Relevant Italian National Interest, aims to illustrate their definitional aspects and its evolution, and how to sustainably organize the territory in order to accommodate those paths.

Studies on experiential paths find their roots in the disciplines of psychology and those of the economy, and, more recently, in the disciplines which study the territory. The synthesis of the case study of Pompeii, in course of development, devoted to identify the cultural and identity resources in order to both widen and differentiate those archaeological ones and create a smart sustainable experiential knowledge of the territory, concludes the contribution.

\section{Definition}

Studies on experiential paths are rooted in the disciplines of psychology and those of the economy, subsequently evolved in the disciplines that study the territory.

David Kolb ([4], Kolb et al. [5]), one of the greatest scholars of Experiential Learning in the field of psychology, defines learning as "continuing education of the individual", taking advantage of the various connections that are created between education, work and development of a person. The individual in this way obtains a "system of skills through experiential methodologies, which lead to the development of educational goals adhering to the real world of work". Experiential learning is a modality of learning which is based on experience, meant in its 
cognitive and sensory sense. The subject, as an active protagonist, through the testing of situations, tasks and roles, organizes its resources and expertise to the pursuit of a goal. Experiential learning also allows to improve, through creative skills, aptitude for problem solving, develop adaptive behaviours, and enhance constructive behaviours. These skills constitute a set of experience that can be used as a starting point for further changes (Wikipedia). The definition of "experiential" in the field of economic studies assumes a more extensive meaning and is more akin to the territory. It is possible to recognize three periods - since the $80 \mathrm{~s}$ onwards - in which the consumer behaviour has its own evolution as a result of the experience. The term "experiential" is introduced in 1982 "as an approach that focuses on the symbolic, aesthetic and hedonistic nature of consumption, and which is based on the conception of the experience of consumption as an activity aimed at searching for amusements and sensations" [5]. Later, it is shown that the rational and the emotional component can co-exist and influence the degree of satisfaction, introducing in the consumer an experiential vision. The recognition of the importance of variables such as the emotions that bring pleasure to the need for the use of the product as well as the action of purchase become important to the design of the product. As noted by the study of Capitello et al. [6] new terms are introduced such as shopping experience [6, 7], the Internet shopping experience [8] until the customer experience aimed at creating competitive value. In the 2000s the new studies on customer experience proposes a holistic experience between the person and the offer by the company in order that every moment of the process of knowledge acquisition and the product is being lived out in an excellent manner. This approach, on the one hand offers a significant competitive advantage to the company, on the other requires a more accurate study of the offer in terms of experience. It also requires that the company is able to achieve differentiated offerings in order to meet different needs, leading to the "customization" and an increase in terms of time and costs compared to the common design of the offer. Determining factors in this regard are, besides the quality and reputation of the proposed product, the attractiveness of the place and the functionality of its services, and intangible values such as tradition and hospitality of the population [5]. The experience of the place becomes an integral part of the product experience. The enhancement of products [9] "assumes a meaning which goes beyond the simple sale of material goods. It covers the supply of complex experiences (...) enriched by intangible elements capable to stimulate and involve the sensory and experiential component of consumption". It deals with attracting people to the places where local products are made by inserting the products in the most extensive offers covering the entire territorial system of reference. Overall supply is not given by just a single product but also by a bidding system where one or more undertakings, local institutions, entertainment activities promote a new image of the area. The demand changes in demand for experiences which in turn requires appropriate host structures which can contain it. 


\section{Organization of territorial system}

The construction of a territorial system in support of experiential activities requires the definition of appropriate network modalities.

In the study of Splendiani et al. [10] while it refers to the promotion of local products, a logic of interest is shown which can also be extended to other types of cultural "products".

As is explained by Montella [11] "In the case of local systems for the promotion of local products, the most appropriate organizational models appear" variable geometry, "according to different thresholds of efficiency and effectiveness that characterizes the different species of internal processes to the network".

It is possible to identify two methods of construction of the network: in the first case it is characterized by a logic of organization from the bottom of spontaneous type that consists in the aggregation of different actors on a common idea of task management to the end of the realization of a common project; in the second case, mainly top-down, the construction of the system provides a governing body that manages the operation of aggregation of the different actors and planned activities and is expected to last over time $[11,12]$.

The purpose of the supply system which is built makes the user no longer passive subject of standardized economy, but active and involved in the process of production and consumption of the product, as well as able to create value. The concept of value is extended also to the local stakeholders who contribute to the construction of the network. The value in this way "is created jointly between the parties involved (...) transcending the boundaries between functions and specialized disciplines and taking a holistic view that, at the district level, it implies a setting of network marketing, where there are no buyers and sellers, but partners who exchange resources to carry out jointly interdependent activities aimed at the preparation of experiences" [9]. The "exhibition" of the experience has an operative potential in the support of the development of creative forces. The scientific landscape in this sense finds its origins in studies of the economist Florida but it has evolved to the impact that the creative approach has on the territory $[13,14]$.

Florida argues that the more cities are able to seem attractive to the creative class of workers and managers in the various sectors of economy such as art, design, fashion and advanced technologies services, the greater are the chances that those cities can successfully to face the challenges of competition among cities imposed by globalization.

However it must be understood that creativity is found not only in the typical characteristics of the entrepreneurial spirit but also in forms such the dissemination of behaviours that is favourable to cultural exchange as well as the enhancement of lifestyle diversity. As a matter of fact, the city is an organism, any element is inextricably interwoven and planning is based on how people feel the city from an emotional and psychological point of view. Its guiding principle is placemaking rather than the urban development [14]. In this way, the creative city recognises the complexity and addresses the spatial, physical and land use conditions which 
help people to think and act with the use of imagination and live the city as a satisfying experience.

The creative city is moving from a city where the creative class attracts new economies to cities where the creative class generates new economies, producing new identities and new geographies based on culture, arts, knowledge, communication and cooperation. The objective is to nourish creativity within the city, and produce a creative class from inside rather than attract one from outside. In this framework there is the creative milieu, intended as a place, which may correspond to the whole city or to a part thereof and which contains the characteristics necessary for generating a flow of creative ideas and innovations. In the creative milieu, clusters and districts capable of strengthening the cultural urban structure can be developed $[15,16]$. The creation of a creative district must be accompanied by the construction of lines of action to make the factors of development, enabled by the cluster, consistent with identity and sustainable growth of the city [17].

As a matter of fact, the development of a creative district cannot leave aside from a sustainable development intended in economic, social and environmental sense, which are meant as conditions which are equally important and interdependent for sustainability [18].

Economic sustainability can be defined as "the ability to generate income, profits and work inside a system of equal opportunities for all the elements of society, inside a model which enhances and increases the resources of territory, and furthermore does not produce a collapse of the same in quantitative and qualitative terms". The characteristics of territory, seen as a complex system where the tangible and intangible cultural resources become elements of a chain of added value, assume a key role in the development of the local system. In this way the district, starting from the elements of territory and their enhancement and promotion, will present characteristics of economic sustainability in the long term.

The social sustainability is the "ability to ensure welfare conditions and opportunities of growth equitably distributed in society". The setting up of a model of development based on the enhancement of culture fosters social regeneration of the area, generating in people a perception of belonging. The cultural production and use perform functions of generation and dissemination of creative thinking. Furthermore this use provides tools for the growth of individual opportunities by creating a process for the social sustainable development of territory.

With respect to environmental sustainability, the territory should be understood in its various historical and cultural values, and in its tangible and intangible capitals. In fact, territory is characterized by both capitals and its identity cannot leave apart from them. However, even if the consequences of exhausting of material resources on the nature of territory are known, at regards those immaterial are less evident, although they are as much important, and indeed ensure maintenance of those material. It is therefore necessary to create a close relationship between production systems and central territory, so that companies do interact - inside the values-chain - the processes which generate value for territory $[18,19]$. 


\section{Case study: evolution in experiencing the typical - the smart landscape}

The detailed organization of the experiential paths is devoted to raise awareness in the inhabitants of the places involved and promote a territory through its products and cultural values, in an innovative way.

One of the first examples of this is constituted by typical paths, which are aimed at the promotion of local products in a logic of their emphasis on the experiential dimension and the offer of the territory of which they are the expression. The sense of the paths of the typical lies in the desire to introduce a product and together obtain social and symbolic benefits. As regards, the Wine Routes, introduced by the Italian national law no. 268/1999 - Discipline of the Wine Routes, are an example of interest [20].

The paths centred on the experience of typical products are an example of negotiation between the various activities of exploitation of the resources of a territory which have in common the desire to integrate the range of territory with that of products. These also represent an important opportunity for local development of both disadvantaged and characterized by marginalization areas, in which such projects can convey interests of the institutions, producers and inhabitants for joint projects. The actors involved, motivated by the idea of turning their offer in a broader context of users, are oriented to the construction of a network of relationships with manufacturers and other entities participating in the initiative to promote the area. The success of the strategy is given by the willingness and ability to co-ordination of individual producers, whose synergy can be a real added value and experiential territory [9]. The numerous initiatives throughout Italy, including those of Trentino are a prime example, demonstrating the interest in this type of trails. Web sites related to the wine trails provide detailed information about the different modes of knowledge of the area and products, allowing the user to make a choice in relation to the type of experience that awaits him. In this respect, according with the case study area presented in the following, there is the Vesuvius Wine Route (http://www.stradadelvinovesuvio.com/) aimed at the enhancement of wine and other typical products of the territory of the Park of Vesuvius together with the natural resources and landscapes.

A different use of the experiential component of the road has been studied more recently by architects and planners who have developed theories on the perception of the place introduced by Kevin Lynch [21]. As reported in the study by Degen and Rose [22], the English agenda has given considerable attention to the quality of urban design whose assumption is that it comes directly by the place experience of the people: "a good design can help to create lively places with a distinctive character, streets and public spaces safe, accessible, pleasant to use and at human scale, and places that inspire a positive atmosphere, thanks to the imagination and sensitivity of the designers" [23]. The authors also point out the importance concerning the urban transformations of the built environment as a reflection not only of the political, economic and cultural changes but of the "everyday experience that people have of the urban space". The senses are part of 
everyday life of the people and the sensory experience which it is lived in a place let it to remember or less in a pleasant and distinctive way [24].

Urban studies agree on the fact that, increasingly, the goal of the project interventions in the urban space is to alter the experience of that space for its residents. Urban environments are increasingly designed to be distinctive, trying to create memorable sensory experiences for the people who use them. Even people who visit ordinary urban centres can describe a series of emotional experiences concerning those places given by the five senses. And to place these experiences can be very different from one place to another. The experience can also vary with respect to the means of transport or pedestrian cross of a place.

The sensory experience may also be used for the spectacularization of a place and its commercialization, as in the case of "brandscapes" [25], leading to possible cloning of places that inevitably resemble each other and are not able to involve people who move into them [26].

To complete the experience of a place and its urban environment is necessary, as claimed by Seremetakis [27], resorting to acts of memory. Recalling how such a place can be different in the past is referred to the environment in its current form, but it also raises in relation to how it looked in the past. Or recognizing that a historic example is just like the other town centres and shopping malls is defined as a "type" rather than unique urban environment. As sustained by Eizenberg [28], "the continual remembrance of other places and previous surveys in the same place, whether a person assimilates in place both experienced and constantly refers to other places elsewhere".

Nowadays, new tools are used in order to support the knowledge of places. The introduction of new technologies has had numerous hits on the deepening of the study of the territory.

The emergence of internet as a medium of communication in Europe in the last twenty odd years has not only produced the dematerialization of the territory and the cancelling out of physical distance but has also opened up spaces and their users to new meanings and uses [30]. In a time of economic crisis its ability to reduce costs and speed up relation times has increasingly established it as not just a tool but a method for achieving new interpretations of the territory and forms of socialization $[31,32]$.

The use of internet has led to a different approach to citizen participation. Community hubs, network thinking and social networks are only some of the current relational modalities among web communities. High tech infrastructures are used in a new culture of exchange, creating new possibilities of interaction within the communities. The tension that may result can have outcomes which are difficult to foresee, introducing unexpected features of territorialization and contextualization. Thanks to the innovatory contribution of these infrastructures territorial usage is being reorganised, creating contexts where social exchange comes to replace the more traditional contexts. Such processes are not easy to identify because the visible evidence does not always correspond to the transformations in progress.

Such cyber communities have the common goal of supporting specialised social groups which are often geographically distant [33]. The success of these 
cyber groups is due in the first place to the fact that the networks support "imaginary communities" [34] without the barriers imposed by the physical urban space. In this perspective internet is the means that has enabled the development of social networks and led some to speculate about a global society based on networks [35]. One of the uses of new technologies and the network is augmented reality: using physical and virtual tools, it is designed to enrich "human sensorial perception by means of information, generally manipulated and conveyed electronically, which would not be perceptible using the five senses" [36]. There are in fact many combinations of physical and virtual that can be implemented, to fulfil a range of different uses.

In this direction, it will spawn the smart cities [3]. Infrastructure we have become accustomed to using in a different manner by the cyber city is at the heart of what today is known as the "smart city", in which the whole range of technologies are at the service of the city both to improve the quality of life and ensure its sustainability. In this case the hybridizations vary widely in terms of both significance and application, so that the issues are at times hard to define.

They are put in order the elements of the tangible and intangible assets that can contribute to the attractiveness of the city, creating a vision of experiential paths and parts of the city. This view is favoured by the presence of a quality urban environment and a creative class.

The experiential routes are an example of smart use of ICT as a tool to support the local knowledge through interactive and multimedia devices. An interesting example in this sense is the "project track" of Pisa (within the PIUSS, www.pisa2015.org), aimed at promoting tourism with pedestrian paths of cultural value supported by multimedia tools. The routes include the use of multimedia kiosks with Wi-Fi access with tourist and cultural information through mobile apps. In this way there is a system for the use of cultural heritage, organized in an innovative enhancement of the values and symbols of the area and in a sustainable manner [37].

In this direction the virtual path of Pompeii is proposed. The path is aimed at presenting Pompeii from a different point of view which encourages the enjoyment of this place starting from its identity resources not related only to its archaeological site but also and in particular to its cultural and local roots [38]. The resources are collected by the use of a tablet through the Div@ter dynamic and interactive platform for the complex-sensitive management of the qualitative data of a territory (www.divater.it). The Open Source platform, in course of development in the framework of POR FESR Lazio Region 2007/2013 Axis 1 Activity 1.1), allows to import tangible and intangible spatial data from different sources, integrate them with information provided by the users, calculate indicators and represent the information in interactive and immediately understandable maps. Div@ter is a Geographical Business Intelligence tool devoted to the re-design of the territory, which is conceived as a unique platform with different entry points, both private and public: for local authorities, professionals and citizens. The information collected and systematized in the course of several surveys, questionnaires and analysis is summarized in the maps 
in the form of symbols, connected to multimedia database which can be continuously updated [38].

The main path which has been identified in Pompeii is aimed at reconnecting the public spaces - discovering those more interesting and enhancing those more hidden - between the archaeological site and the religious sanctuary. The network of public spaces with their different identities constitutes both a suitable cultural connection between the two kinds of attractions and an experiential path through the enhancement of local products [40-43]. The public spaces are smartly connected each other and related to sensors and/or virtual tools posed in the places where the history, curiosity, perceptions and information on local products are explained and exhibited. The idea is to attract people in a visit which wholly involve the experience of Pompeii and its less known landscape. The possibility to interact with the smartphone or tablet and live photo and comments on the visit enriches the experience of visitors [44-47]. The paths are thought in continuity with the actions foreseen by the Great Pompeii Project, Interregional Operative Programme "Cultural and natural attractors and tourism" (FESR2007-20013, POIn). That project is aimed at transforming the touristic identity of Pompeii, which will not be only the main archaeological site of the ancient Rome period but the more advanced cultural centre at the international level in order to know life, use and customs of that period.

\section{Conclusion}

The article explains the concept of experiential path, starting from the requirements of the HUL recommendations of UNESCO and explaining its definition. This concept has its origins in studies of psychologists, to continue with those of economists and then passed to those of urban planners. In this regard, the starting point is the perceptual study of Kevin Lynch, and then developed in more recent times by the studies on urban design.

The article has also shown some of the main examples of paths ending with the illustration of the smart ones, which use multimedia technologies that support the development of local resources of an area in innovative way. These are of specific interest for the object of the proposed study of Pompeii.

The construction of experience starts from two assumptions, the creation of networks from bottom-up and top-down. While in the first case, a combination of businesses, stakeholders, institutions comes from the bottom allowing the participation of different actors at all stages of the process, in the second case the creation takes place by decision of a network that conveys interests, actors and economies. In both cases, the success of the operation should be thought in terms of sustainability understood in its threefold sense, taking care not to consume the cultural resources and environmental landscape and to engage in decision-making people who live territories as well as the companies that produce the products.

Finally, the use of technological tools must has the function of increasing the potential for innovation and regional competitiveness of Pompeii and not of 
simplification of the information or of marketing operations. The idea is to attract people in a smart and perceptive visit which wholly involve the experience of Pompeii and its lesser known landscape.

\section{References}

[1] UNESCO, Recommendation on the Historical urban landscape, 2011, http://unesdoc.unesco.org

[2] Florida R., The rise of the creative class. And how it's transforming work, leisure, community and everyday life. Basic Books: New York, 2002.

[3] Duany, A. Speck, J., Lydon M., The Smart Growth Manual. McGraw-Hill: New York, 2010.

[4] Kolb, D. A. Experiential learning: Experience as the source of learning and development. Prentice-Hall: New Jersey, 1984.

[5] Kolb, D.A., Rubin, I.M., \& McIntyre, J. (Eds.), Organizational psychology: An experiential approach. Prentice Hall: Englewood Cliffs, N.J., 1971.

[6] Capitello, R., Castellani, P., Rossato, C., "Territorio, impresa e consumatore: percorsi esperienziali nelle imprese vitivinicole", XXIV Congresso annuale di sinergie. Università di Salento: Lecce, 2012.

[7] Falk P., Campbell, C., The Shopping Experience. Sage: London, 1997.

[8] Menon S., Kahn B., "Cross-Category Effects of Induced Arousal and Pleasure on the Internet Shopping Experience", Journal of Retailing, 78, 2002.

[9] Rieunier S. (ed.), Le marketing sensoriel du point de vente. Dunod: Paris, 2002.

[10] Splendiani, S., Pencarelli, T., Franch, M., De Salvo, P., Calzati, V., Splendiani, S., La valorizzazione del territorio in ottica esperienziale attraverso i percorsi del tipico: riflessioni teoriche ed evidenze empiriche in Italia, Proceedings of Aidea, 2013.

[11] Montella M., Valore e valorizzazione del patrimonio culturale storico, Electa: Milano, 2009.

[12] Golinelli C. M., Il territorio sistema vitale. Verso un modello di analisi, Giappichelli, Torino, 2002.

[13] Sepe, M., "Creative Urban Regeneration between Innovation, Identity and Sustainability", International Journal of Sustainable development, 12 (2-3-4), 2009.

[14] Sepe, M., "Urban history and cultural resources in urban regeneration: a case of creative waterfront renewal", Planning Perspectives Journal, 28 (4), $2013 b$.

[15] Landry C., "The creative city: its origins and futures", Urban Design Journal, 106, 2008.

[16] Carta M., Creative City. LISt: Barcelona, 2007.

[17] Florida R., Cities and the creative class, Routledge: London, New York, 2005.

[18] Ferilli G., Pedrini S., "Il distretto culturale evoluto alla base dello sviluppo sostenibile del territorio", Pre Proc. of XII Convegno Internazionale 
Interdisciplinare Volontà, libertà e necessità nella creazione del mosaico paesistico-culturale, Cividale del Friuli - UD, 25-26 October, 2007.

[19] Nijkamp P., Perrels A.H., Sustainable Cities in Europe. Earthscan: London, 1994.

[20] Nocifora E., de Salvo P., Calzati V. (Eds), Territori lenti e turismo di qualità. Prospettive innovative per lo sviluppo di un turismo sostenibile. Franco Angeli: Milano, 2011.

[21] Lynch, K., The image of the city. Mit Press: Cambridge, 1960.

[22] Degen, M. M. and Rose, G. "The sensory experiencing of urban design: the role of walking and perceptual memory". Urban Studies, 49(15), pp. 3271-3287, 2012.

[23] DETR/CABE By Design: Urban Design and the Planning System: Towards Better Practice. DETR, London, 2000.

[24] Lefebvre, H. The Production of Space. Oxford: Blackwell, 1991.

[25] Klingman, A. Brandscapes: Architecture in the Experience Economy, MIT Press: Cambridge, 2007.

[26] Lehtovuori, P., Experience and Conflict: The Production of Urban Space. Ashgate: London, 2010.

[27] Seremetakis, N., The Senses Still: Perception and Memory as Material Culture in Modernity. Chicago University Press: Chicago, 1994.

[28] Eizenberg, E., "Remembering forgotten landscapes: community gardens in New York City and the reconstruction of cultural diversity".

[29] Yacobi, H. (eds) Remembering, and Forgetting City Builders. Farnham: Ashgate, pp. 7-26, 2010.

[30] Castells M., The informational city. Blackwell: Oxford, 1989.

[31] Sepe, M. Planning and Place in the City. Mapping Place Identity. Routledge, London, New York, 2013a.

[32] Sepe, M., "Urban history and cultural resources in urban regeneration: a case of creative waterfront renewal", Planning Perspectives Journal 28(4), 2013 b.

[33] Graham, S., Marvin, S., Splintering urbanism: networked infrastructures, technological mobilities and the urban condition. Routledge: London, New York, 2001.

[34] Anderson, B. R., Imagined communities: reflections on the origin and spread of nationalism. Verso: London, 1991.

[35] Frederick, H. H., Global communication and international relations, Wadsworth: Belmont, CA, 1993.

[36] Di Bari, V., Magrassi, P. 2015 weekend nel futuro. Edizioni Il Sole 24 Ore: Milano, 2005.

[37] Peano, A., Voghera, A., "Smart landscape. Una nuova grammatica per la transizione urbana" in Chang T.F.M., Piccinini L.C., Taverna M. (Eds.), Il mosaico paesistico-culturale in transizione: dinamiche, disincanti, dissolvenze, "Paysage Topscape" Overview, 9, 2011.

[38] Sepe M., "Preserving, reconstructing and enhancing the place identity: identifying principles of urban sustainability with placemaker method", 
International Journal of Sustainable Planning and Development, 9(2), 2014.

[39] Sepe M. "Creating smart urban landscapes: a multimedia platform for placemaking", TEMA, special issue June 2014 on the Eighth International INPUT Conference Smart City Planning for Energy, Transportation and Sustainability of the Urban System, pp. 897-907, 2014.

[40] Buttimer, A., Seamon, D., The Human Experience of Space and Place. St Martin's Press: New York, 1980.

[41] Carmona, M., "Design coding and the creative, market and regulatory tyrannies of practice" Urban Studies, 46, pp. 2643-2667, 2009.

[42] Castello, L., Rethinking the Meaning of Place: Conceiving Place in Architecture-urbanism. Ashgate, 2010.

[43] Cronin, A., Hetherington, K., Consuming The Entrepreneurial City: Image, Memory, Spectacle. Routledge: London, 2008.

[44] Feld, S., "Places Sensed, Senses Placed", in D. Howes (ed) Empire of the Senses, Oxford: Berg, 2005.

[45] Grant, J., "Experiential planning", Journal of the American Planning Association, 75, pp. 358-370, 2009.

[46] Zardini, M., “Toward a Sensorial Urbanism”, in: M. Zardini (Ed.) Sense of the City, Montreal: Lars Muller Publishers, pp. 17-33, 2008.

[47] Sepe M. and Pitt M. The characters of place in urban design. Urban Design International, advance online publication 8 January 2014; doi: 10.1057/udi.2013.32, 2014. 